\title{
DESENVOLVIMENTO DE MUDAS DE MARACUJAZEIRO-AMARELO OBTIDAS DE SEMENTES EXTRAÍDAS POR FERMENTAÇÃO ${ }^{1}$
}

\author{
GLEIBSON DIONÍZIO CARDOSO², JOSÉ CELESMÁRIO TAVARES ${ }^{3}$ \\ REGINA LÚCIA FÉLIX FERREIRA ${ }^{3}$, FRANCISCO AUGUSTO ALVES CÂMARA ${ }^{3}$ \\ GILCIMAR ALVES DO CARMO ${ }^{5}$
}

\begin{abstract}
RESUMO- Com o objetivo de avaliar o efeito da fermentação na obtenção da semente do maracujá-amarelo sobre a emergência de plântulas e o desenvolvimento de mudas, foi conduzido um experimento em casa de vegetação no Departamento de Fitotecnia da Escola Superior de Agricultura de Mossoró, Mossoró-RN, Brasil. O delineamento experimental usado foi em blocos casualizados completos com sete tratamentos e quatro repetições. As características avaliadas foram porcentagem de emergência; número de dias para atingir $50 \%$ de emergência; vigor das sementes, avaliado pelo número médio de dias para atingir o máximo de emergência; altura das plântulas; diâmetro do caule; número de folhas; comprimento da raiz pivotante; peso da matéria seca da parte aérea e raiz. $\mathrm{O}$ desenvolvimento das mudas não foi influenciado pela extração das sementes por fermentação. A fermentação do arilo durante 3 a 6 dias promoveu maior vigor de sementes e emergência de plântulas em menor tempo que as sementes obtidas sem fermentação.
\end{abstract}

Termos para indexação: Passiflora edulis, germinação, propagação, vigor.

\section{DEVELOPMENT OF SEEDLINGS OF YELLOW PASSION FRUIT OBTAINMENT OF FERMENTATION EXTRACT SEEDS}

\begin{abstract}
With the objective of evaluating the effect of fermentation on obtainment in yellow passion fruit seeds on the plantlets emergency and development seedling, a research was carried in greenhouse in the Fitotecnia Department, ESAM, in Mossoró-RNBrazil. The experimental design was a randomized complete block with seven treatments and four replications. Evaluations were performed emergency percentage, days number to reach emergency $50 \%$, height plantlets, stem diameter, leaf number, length pivotant root, dry weight of part aereal and root. The development of seedling was not influenced by fermentation extract seeds. The fermentation of the flash fruit during 3 to 6 days promoted lager vigour and plantlets emergency at smaller time that unfermentation extract seeds.
\end{abstract}

Index terms: Passiflora edulis, germination, propagation, vigour.

\section{INTRODUÇÃO}

O maracujazeiro é basicamente propagado através de sementes, o que acarreta uma grande variabilidade em suas características, podendo também disseminar uma série de doenças, que comprometem o empreendimento (Rizzi et al., 1998).

O método de extração de sementes mais utilizado é aquele no qual os frutos selecionados são cortados ao meio e a polpa retirada e colocada em um recipiente de vidro, onde permanecem em fermentação natural durante alguns dias para facilitar a remoção do arilo aderente às sementes. No entanto, quando se usa o processo de fermentação na limpeza das sementes, para evitar prejuízos na germinação, o tempo de fermentação não deve ser superior a 72 horas (Teixeira, 1994), com o processo realizado à sombra, em recipiente de vidro ou louça, com duração de 24 a 72 h (Ruggiero et al., 1996; Rizzi et al., 1998). A fermentação tem a finalidade de facilitar a separação entre as sementes e a mucilagem que as envolve e geralmente exige um período de 2 a 6 dias (Lima et al., 1994; Maldonado et al., 1999). A maior duração da fermentação (3 a 5 dias) é justificável quando há eliminação de alguns patógenos superficiais e não danifica fisicamente nenhuma estrutura interna da semente (Melleti e Maia, 1999). Além disso, a germinação de plântulas normais e o vigor das sementes extraídas por fermentação são maiores que sementes extraídas sem fermentação (Tsuboi e Nakagawa, 1992). O investimento em mudas e ou sementes selecionadas, além de ser importante componente do investimento total na fruticultura, por constituir um pré-requisito fundamental ao sucesso da atividade, é também um dos itens mais expressivos, especialmente em capital, principalmente nos empreendimentos que visam a atingir as parcelas mais nobres do mercado consumidor (David et al., 1999). Em função disso, instalou-se o presente experimento com o objetivo de avaliar o efeito do período da fermentação das sementes do maracujáamarelo na emergência e no desenvolvimento de mudas.

1 (Trabalho 028/2001). Recebido: 02/02/2001. Aceito para publicação: 04/10/2001. Trabalho extraído da Monografia do primeiro autor.

2 Eng $^{\circ}$. Agr ${ }^{\circ}$. mestrando em Fitotecnia da Universidade Federal da Paraíba. e-mail: gleibson75@hotmail.com

3 Professores Adjuntos da Escola Superior de Agricultura de Mossoró. Caixa Postal 137, Bairro Costa e Silva, Mossoró/RN. 4 Eng ${ }^{\circ}$. Agr ${ }^{\circ}$. M.Sc., Doutoranda em Fitotecnia da Universidade Federal de Lavras-UFLA. Rua Francisco Xavier, 414, Vila São Francisco, Lavras-MG. e-mail: reginalff@hotmail.com

5 Eng'. Agro. M.Sc. Fitotecnia/ESAM. e-mail: galcar69@hotmail.com 


\section{MATERIAL E MÉTODOS}

O experimento foi conduzido em casa de vegetação do Departamento de Fitotecnia da Escola Superior de Agricultura de Mossoró, Rio Grande do Norte, durante o período de março a abril de 2000. O delineamento experimental utilizado foi o de blocos completos casualizados, com sete tratamentos e quatro repetições. Os tratamentos foram constituídos pelo tempo de fermentação, variando de 1 a 6 dias, mais a testemunha, e a parcela composta de 45 sementes distribuídas em 15 recipientes. Os frutos selecionados, obtidos em pomares da região, foram cortados ao meio, e as sementes retiradas foram colocadas em 6 recipientes de vidro, para a fermentação natural, durante $1 ; 2 ; 3 ; 4 ; 5$ e 6 dias, respectivamente, e a testemunha (sem fermentação). Após a fermentação, as sementes foram lavadas em água corrente sobre peneiras e colocadas para secar à sombra por dois dias, sobre folha de jornal, e a seleção das sementes foi realizada conforme recomendação de Ruggieiro et al. (1996), colocando-as em um recipiente com água e eliminando as que boiaram. A semeadura foi realizada em 09-03-2000, empregando-se 3 sementes por recipiente, a uma profundidade de $1 \mathrm{~cm}$; posteriormente, quando as mudas atingiram $5 \mathrm{~cm}$ de altura, efetuou-se o desbaste, deixando-se a mais vigorosa. Como recipiente, foi empregado copo descartável com capacidade de $300 \mathrm{ml}$, e como substrato, utilizou-se de uma mistura comercial, constituída de matéria orgânica, composto e vermiculita expandida.

Durante 30 dias, em contagens diárias, foram avaliadas as seguintes características: percentagem de emergência (PE): feita com a população final, até 30 dias após a semeadura, com a contagem diária do número de plântulas emergidas por parcela; velocidade de emergência, avaliada pela população inicial, feita através do número de dias para atingir $50 \%$ de emergência (ND): em contagens diárias das plântulas emergidas (Silva et al., 1993). Foram consideradas plântulas emergidas aquelas cujos cotilédones estavam inteiramente fora do solo; vigor de semente (NM): avaliado pelo "número médio de dias para a emergência".

Aos 30 dias após a semeadura, empregando-se 15 plântulas por parcela e ao acaso, foram avaliadas: altura da muda (ALT): medindo-se do colo da plântula até a gema apical, obtida com uma régua milimétrica; diâmetro do caule (DAM): determinado a um centímetro do colo da plântula; número de folhas (NF): partindo-se da folha basal até a última folha aberta; comprimento da raiz pivotante (CRP): obtido com o auxílio de uma régua milimétrica, medindo-se do colo até a extremidade da raiz; peso da matéria seca da parte aérea (MSPA) e raiz (MSSR): determinada em uma balança analítica com precisão de $0,0001 \mathrm{~g}$ após acondicionamento em saco de papel e manutenção em estufa a $75^{\circ} \mathrm{C}$, com circulação forçada de ar, até peso constante.

Os dados foram submetidos à análise de variância, teste de Lilliefors para normalidade dos dados, teste de Cochran e Bartlett para homogeneidade dos dados e as médias submetidas ao teste de Tukey, a 5\% de probabilidade, através do "softwere" SAEG. Para as características onde a regressão foi possível, as curvas foram ajustadas através do softwere Table Curve (Jandel Scientific, 1991).

\section{RESULTADOS E DISCUSSÃO}

A percentagem de emergência apresentou uma tendência de aumento com o emprego da fermentação (Figura 1), confirmando o relato de Meletti \& Maia (1999), sugerindo que esse processo não danifica fisicamente nenhuma estrutura interna da semente.

Ao avaliar diferentes métodos para uniformizar a germinação, Tsuboi \& Nakagawa (1992) constataram, sete dias após a semeadura, que as sementes fermentadas, por três dias, apresentaram-se com $82 \%$ contra apenas $70 \%$ naquelas que não foram submetidas a esse tratamento. Como as Passifloráceas são consideradas entre as famílias cujas sementes apresentam dormência, devido aos mecanismos de controle de entrada de água para o seu interior, pode-se atribuir esse efeito a uma possível interferência da fermentação neste processo. Com o aumento do período de fermentação, tornou-se mais fácil a retirada da mucilagem no processo de lavagem das sementes. Este fato, que se constitui numa facilidade para a obtenção de sementes, também foi constatado por Lima et al. (1994) e Maldonado et al. (1999).

A velocidade de emergência (ND), determinada pelo número de dias até que $50 \%$ das plântulas estivessem emergidas (Silva et al. 1993), demonstrou, a exemplo do que ocorreu com a porcentagem de emergência, um efeito positivo da fermentação (Figura 2).

O padrão de comportamento da ND, em função do período de fermentação das sementes de maracujá, foi decrescente. Este efeito positivo da fermentação, entre 3 e 6 dias (Tabela 1), vem confirmar as recomendações de Lima et al. (1994), Maldonado et al. (1999) e Meletti \& Maia (1999), no que se refere ao período de fermentação requerido por essas sementes. Para o vigor das sementes (NMD), determinado pelo número médio de dias para atingir o máximo de emergência, observou-se um padrão de comportamento similar ao obtido na ND (Figura 3).

Ao contrário do que afirma Teixeira (1994), não se constatou nenhum prejuízo na emergência em função do emprego da fermentação por períodos superiores a 72 horas. Pois, conforme dados apresentados na Tabela 1, o maior vigor foi observado entre 3 e 6 dias de fermentação. Este efeito do período de fermentação, provavelmente, pode estar relacionado à inativação de fitorreguladores presentes no envoltório, conforme hipótese levantada por São José (1987), citado por Tsuboi \&

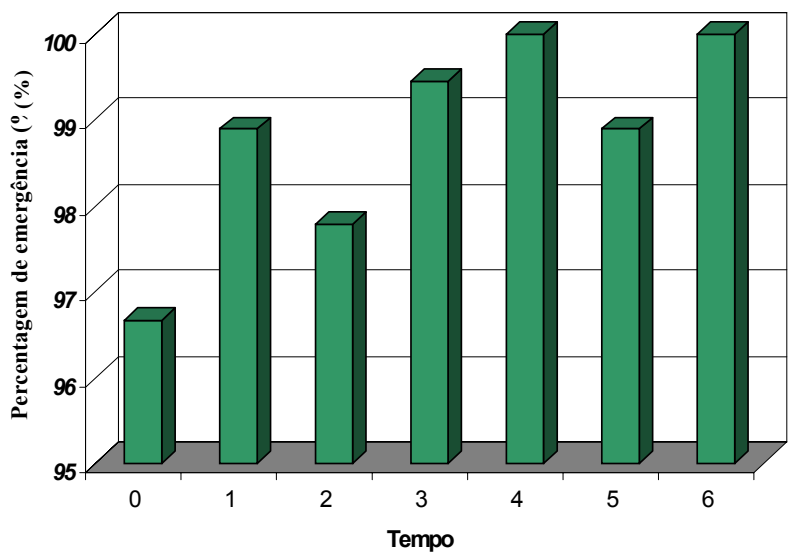

FIGURA 1 - Valores Médios da percentagem de emergência de plântulas de maracujá-amarelo, em função da fermentação das sementes. ESAM. Mossoró-RN. 2000. 
TABELA 1 - Médias da velocidade de emergência (ND); vigor da sementes (NMD); altura da plântula (AP); diâmetro do caule (DC); número de folhas (NF); matéria seca da parte aérea (MSPA); comprimento da raiz pivotante (CRP); matéria seca do sistema radical (MSSR), em função do tempo de fermentação da semente do maracujá-amarelo. ESAM, Mossoró-RN

\begin{tabular}{ccccccccc}
\hline & \multicolumn{7}{c}{ CARACTERÍSTICAS AVALIADAS } \\
\cline { 2 - 9 } TRATAMENTOS & ND & NMD & AP $(\mathrm{cm})$ & DC $(\mathrm{mm})$ & NF & MSPA (g) & CRP $(\mathrm{cm})$ & MSSR (g) \\
\hline T0 (0 DIA) & $2,80 \mathrm{a}$ & $22,06 \mathrm{a}$ & $3,93 \mathrm{a}$ & $1,41 \mathrm{a}$ & $4,45 \mathrm{a}$ & $0,0542 \mathrm{a}$ & $16,34 \mathrm{~b}$ & $0,0275 \mathrm{a}$ \\
T1 (1 DIA) & $2,64 \mathrm{bc}$ & $18,56 \mathrm{abc}$ & $3,98 \mathrm{a}$ & $1,44 \mathrm{a}$ & $4,72 \mathrm{a}$ & $0,0610 \mathrm{a}$ & $17,04 \mathrm{ab}$ & $0,0278 \mathrm{a}$ \\
T2 (2 DIAS) & $2,71 \mathrm{ab}$ & $19,02 \mathrm{ab}$ & $3,98 \mathrm{a}$ & $1,39 \mathrm{a}$ & $4,56 \mathrm{a}$ & $0,0505 \mathrm{a}$ & $17,47 \mathrm{a}$ & $0,0261 \mathrm{a}$ \\
T3 (3 DIAS) & $2,62 \mathrm{bc}$ & $18,04 \mathrm{bc}$ & $4,19 \mathrm{a}$ & $1,45 \mathrm{a}$ & $4,65 \mathrm{a}$ & $0,0609 \mathrm{a}$ & $17,70 \mathrm{a}$ & $0,0275 \mathrm{a}$ \\
T4 (4 DIAS) & $2,54 \mathrm{c}$ & $16,07 \mathrm{bc}$ & $4,16 \mathrm{a}$ & $1,46 \mathrm{a}$ & $4,50 \mathrm{a}$ & $0,0545 \mathrm{a}$ & $16,91 \mathrm{ab}$ & $0,0273 \mathrm{a}$ \\
T5 (5 DIAS) & $2,62 \mathrm{bc}$ & $15,49 \mathrm{bc}$ & $4,01 \mathrm{a}$ & $1,43 \mathrm{a}$ & $4,48 \mathrm{a}$ & $0,0506 \mathrm{a}$ & $17,57 \mathrm{a}$ & $0,0251 \mathrm{a}$ \\
T6 (6 DIAS) & $2,52 \mathrm{c}$ & $15,39 \mathrm{c}$ & $4,13 \mathrm{a}$ & $1,40 \mathrm{a}$ & $4,50 \mathrm{a}$ & $0,0495 \mathrm{a}$ & $17,67 \mathrm{a}$ & $0,0270 \mathrm{a}$ \\
\hline CV \% & 2,22 & 8,50 & 6,56 & 3,00 & 2,88 & 14,25 & 2,35 & 9,33
\end{tabular}

${ }^{1}$ Médias seguidas pelas mesmas letras nas colunas não diferem estatisticamente entre si, pelo teste de Tukey, ao nível de 5\% de probabilidade.

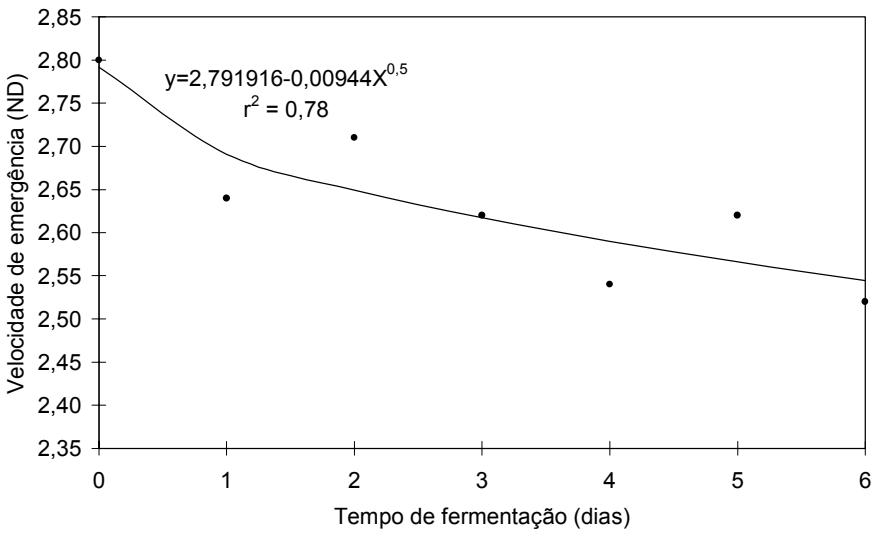

FIGURA 2 - Velocidade de emergência em função do período de fermentação da semente do maracujá-amarelo. ESAM. Mossoró-RN. 2000.

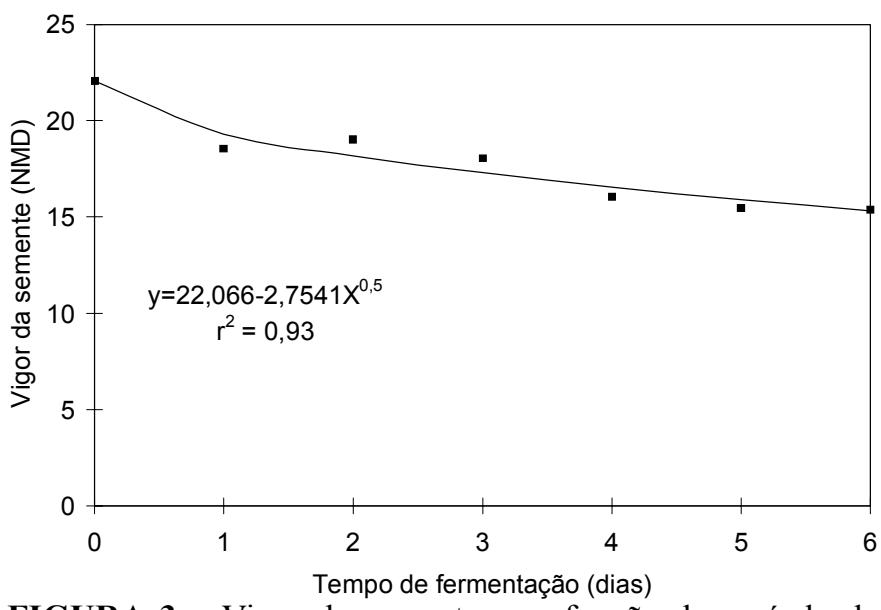

FIGURA 3 - Vigor da semente em função do período de fermentação da semente do maracujá-amarelo. ESAM. Mossoró-RN. 2000.
Nakagawa (1992).

A altura das plântulas e o diâmetro do caule, aos 30 dias após a semeadura, não variaram em função do tempo de fermentação das sementes (Tabela 1). Mesmo sem diferir estatisticamente, contatou-se uma tendência de aumento na altura das plântulas com o tempo de fermentação. Tal comportamento pode ser atribuído ao efeito positivo da fermentação na velocidade de emergência e no vigor da semente, confirmando a hipótese de que a variação de diâmetro é resultado direto do volume de substrato disponível à muda (Araújo, 1995; Dantas, 1995; Chagas, 1997). Não foram observadas variações neste parâmetro, uma vez que o volume do recipiente utilizado foi o mesmo em todos os tratamentos.

O número de folhas e massa seca da parte aérea não diferiram em função dos tratamentos (Tabela1).

Essa tendência de comportamento vem reforçar a hipótese de que a fermentação das sementes de maracujá, por até seis dias, não as comprometeu, ao contrário do que afirmam Teixeira (1994) e Manica (1981).

O comprimento da raiz pivotante foi influenciado pela fermentação; entretanto, não se observaram diferenças em função do tempo empregado (Tabela 1). Pode ser explicado pela velocidade de germinação das sementes que foram submetidas ao tratamento.

Com relação à massa seca do sistema radicular, não foram observadas diferenças entre os tratamentos (Tabela 1). Isto demonstra, a exemplo do que foi constatado para número de folhas e massa seca da parte aérea, que a fermentação não interferiu no desenvolvimento das mudas.

\section{CONCLUSÕES}

Considerando-se as condições nas quais o experimento foi realizado, pode-se concluir:

1 - A fermentação facilitou a retirada da mucilagem sem prejudicar a emergência das plântulas de maracujá-amarelo. 
2 - A fermentação promoveu um maior vigor das sementes e emergência de plântulas em menor tempo que as sementes sem fermentação.

3 - O desenvolvimento das mudas não foi afetado pela fermentação das sementes.

\section{REFERÊNCIAS BIBLIOGRÁFICAS}

ARAÚJO, M. V. Tamanho do recipiente e período de permanência na formação de mudas de maracujazeiro (Passiflora edulis. Sims. flavicarpa Deg). 1995. 23 f. Monografia (Trabalho de Graduação em Agronomia) Escola Superior de Agricultura de Mossoró, Mossoró, 1995.

DANTAS, S. da C. Efeito de recipiente de diferentes tamanhos no crescimentos de mudas de cupuaçuzeiro (Theobroma grandflorum Willd. Ex. Spreng. Schum.). 1995. 39f. Dissertação (Mestrado em Agronomia) Escola Superior de Agricultura de Mossoró, Mossoró, 1995.

DAVID, D. V.; SILVA, J. M. A.; SILVA, P. M. (Coord.), Diagnóstico de produção e comercialização de mudas e semente de espécies frutíferas na região Nordeste do Brasil. Viçosa, MG: UFV; DER; FUNABE, 1999.215p. il.

JANDEL, SCIENTIFIC, user's manual Califórnia, 1991. 280 p.

LIMA, A. de A.; BORGES, A. L.; SANTOS FILHO, H.P.; SANTOS, L. B. dos; FANCELLI, M.; SANCHES, N. F. Instruções práticas para o cultivo do maracujazeiro. Cruz das almas, BA: EMBRAPA -CNPMF, 1994. 49p (Circular Técnica, 20).
MALDONADO, J. F. M.; FERNANDES, S. G.; CARVALHO, S. M. P.; COSTA, R. A.; OLIVEIRA, L. A. A.; SARMENTO, W. R. M.; CUNHA, H. (Coord.). A cultura do maracujá: perspectivas, tecnologias e viabilidade. Niterói,RJ: PESAGRO-RIO, 1999. 34p. (Documento, 49).

MANICA, I. Fruticultura Tropical: maracujá - São Paulo. SP. Agronômica Ceres; 1981. 160p.ilusão.

MELETTI, L. M. M.; MAIA, M. L. Maracujá: produção e comercialização em São Paulo. Campinas, SP: Instituto Agronômico, 1999. 64 p. (Boletim Técnico, 181).

RIZZI, L. C.; RABELO, L. R.; MORINI FILHO, W.; SAVAZAKI, E. T.; KAVATI, R. Cultura do maracujá-azedo. Campinas, SP: CATI, 1998. 54p. (Boletim Técnico, 235).

RUGGIERO, C.; SÃO JOSÉ, A. R.; VOLPE, C. A.; OLIVEIRA, J. C.; DURIGAN, J. F.; BAUMGARTNER, J. G.; SILVA, J. R.; NAKAMURA, K.; FERREIRA, M. E.; KAVATI, R.; PEREIRA; V. de P. Maracujá para exportação: aspectos técnicos da produção. Brasília: EMBRAPA SPI, 1996. 64 p. (Publicação Técnicas Frupex, 19).

TEIXEIRA, E. G. Maracujá In: ITAL (ed): Cultura, Matéria-prima, processamento e aspectos econômicos. 1994. 2. ed. rev. ampl. Campinas,SP: ITAL, 1994. p.1-142; il. (Série Frutos Tropicais, 9).

TSUBOI, H.; NAKAGAWA, J. Efeito da escarificação por lixa, acido sulfúrico e água quente na germinação das sementes de maracujazeiro-amarelo. Revista Cientifica, São Paulo, v. 20, n. 1, p. $63-62,1992$. 